\title{
UTILIZAÇÃO DE ELETROFORESE (SDS-PAGE) PARA ESTUDO DE PROTEÍNAS DE TECIDO MUSCULAR DE LULA "IN NATURA" E PROCESSADA
}

\author{
ALESSANDRO DOS SANTOS FRAZÃO* \\ MARILIA PENTEADO STEPHAN** \\ ANGELA APARECIDA LEMOS FURTADO***
}

\begin{abstract}
No presente trabalho foram estudadas as modificações das proteínas no tecido muscular de manto de lula (Doryteuthis plei - BLAINVILLE, 1823), "in natura", préprocessado $\left(95^{\circ} \mathrm{C} / 5 \mathrm{~min}, \mathrm{NaCl} 2 \%\right)$ e processado $\left(120^{\circ} \mathrm{C} /\right.$ $7 \mathrm{~min}, \mathrm{NaCl} 2 \%)$. Também foram analisadas as proteínas solubilizadas naturalmente na salmoura do préprocessamento e do processamento. As amostras foram avaliadas durante período de armazenamento de 90 dias. As proteínas do manto foram extraídas com tampão fosfato $\left(15,6 \mathrm{mM} \mathrm{K}_{2} \mathrm{HPO}_{4} ; 4,3 \mathrm{mM} \mathrm{KH}_{2} \mathrm{PO}_{4} ; \mathrm{pH} 7,5\right)$ e tampão fosfato salino $\left(15,6 \mathrm{mM} \mathrm{K}_{2} \mathrm{HPO}_{4} ; 4,3 \mathrm{mM} \mathrm{KH}_{2} \mathrm{PO}_{4} ; 0,45 \mathrm{M} \mathrm{KCl} ; \mathrm{pH}\right.$ $7,5)$. As proteínas solúveis obtidas foram avaliadas quantitativamente por método colorimétrico. A análise em gel de poliacrilamida contendo dodecil sulfato de sódio (SDS) foi utilizada para caracterizar as cadeias polipeptídicas das proteínas solúveis estudadas. Obtevese padrão de identidade pelo perfil em gel de eletroforese (SDS-PAGE) da lula "in natura", cuja faixa de cadeias polipeptídicas variou de $8 \mathrm{kDa}$ a $222 \mathrm{kDa}$. O padrão de identidade obtido para o manto de lula processada apresentou perfil de cadeias polipeptídicas com 43, 80 e $83 \mathrm{kDa}$. Esse perfil polipeptídico permaneceu estável durante 90 dias, o que evidenciou boa preservação do produto armazenado na forma de conserva.
\end{abstract}

PALAVRAS-CHAVE: TRATAMENTO TÉRMICO; LULA; Doryteuthis plei; PROTEÍNAS.

\section{INTRODUÇÃO}

A comercialização de lula no Estado do Rio de Janeiro ocorre na forma "in natura", mantida sob refrigeração, ou limpa e submetida ao

\footnotetext{
* Mestre em Ciência e Tecnologia de Alimentos, Professor Substituto, Departamento de Química, Universidade Federal Rural do Rio de Janeiro, Seropédica, RJ.

** Pesquisadora, Embrapa Agroindústria de Alimentos, Rio de Janeiro, RJ (e-mail: stephan@ctaa.embrapa.br).

*** Pesquisadora, Embrapa Agroindústria de Alimentos, Rio de Janeiro, RJ (e-mail: afurtado@ctaa.embrapa.br).
} 
congelamento, sendo encontrada principalmente nas peixarias e nos supermercados. A utilização da lula em conserva contribui para a distribuição do produto no mercado interno, sem a necessidade de cadeia de frio (AOYAMA et al., 1996; NAKASHIMA et al., 1996). Além disso, constitui alternativa de aproveitamento da capacidade de processamento instalada, reduzindo o tempo ocioso dos equipamentos.

O tratamento térmico causa modificações na textura da lula decorrentes da desnaturação da estrutura protéica, componente do tecido muscular desse fruto do mar. As proteínas majoritárias desse tecido, a miosina e a actina, são miofibrilares e estão diretamente envolvidas no processo de locomoção do molusco (KONNO, ARAI e WATANABE, 1979).

Várias modificações têm sido verificadas nas proteínas miofibrilares do tecido muscular do pescado capturado, principalmente quando submetido ao calor (KUGINO e KUGINO, 1995; NAITO et al., 1996). Essas modificações podem se refletir no perfil de bandas protéicas apresentado na eletroforese, como decorrência de alterações das próprias proteínas musculares (STANLEY e HULTIN, 1982; ANDO et al., 1999).

Alterações no tecido muscular também têm sido verificadas em função do resfriamento (HSU et al., 1993; UENG e CHOW, 1998). ANDO et al. (1999) relataram mudanças na estrutura e na firmeza do tecido muscular do manto de lula (Loligo bleekert) refrigerado a $5^{\circ} \mathrm{C}$.

Para STANLEY e SMITH (1984) o aquecimento do tecido das espécies de lula Illex illecebrosus e Loligo pealeiem água fervente por 32 minutos acarretou o aparecimento de material granulado, originado pela desnaturação das proteínas na superfície mais lisa das fibras. 0 aquecimento também produziu desnaturação da proteína contrátil e o conseqüente endurecimento e aumento da densidade do manto. Entretanto, nenhuma análise molecular do perfil de bandeamento protéico foi realizada por esses autores.

O processo térmico gera produto comercialmente chamado estéril, pois embora possam ser encontrados microrganismos viáveis as condições gerais são desfavoráveis para o seu desenvolvimento. Os microrganismos presentes não irão causar deterioração, ou efeitos nocivos ao consumidor (AKTERIAN, 1996). Essa operação é utilizada para preservar os alimentos visando, geralmente, a inativação de microrganismos patogênicos e deteriorantes (NAVANKASATTUSAS e LUND, 1978). 
O presente trabalho teve como objetivo identificar as principais proteínas do manto de lula, tanto as liberadas na salmoura quanto as extraídas do próprio manto, antes do tratamento térmico e após seu processamento. Pretendeu-se também verificar a estabilidade da conserva durante armazenamento de 90 dias, mediante variação do perfil protéico do manto de lula.

\section{MATERIAL E MÉTODOS}

\subsection{MATÉRIA-PRIMA}

Foram utilizadas frações protéicas extraídas do tecido muscular do manto de lula Doryteuthis plei (BLAINVILLE, 1823) (ROPER, SWEENEY e NAUEN, 1984). As lulas, adquiridas no Mercado São Pedro (Niterói-RJ), foram limpas e os mantos estocados a $-18^{\circ} \mathrm{C}$ até o momento do uso. Durante todo o período de utilização as amostras foram mantidas em baixa temperatura. Já o manto da lula em conserva foi processado em um único lote na área de engenharia da Embrapa Agroindústria de Alimentos.

\subsection{PREPARO DA AMOSTRA E PROCESSAMENTO}

O manto da lula foi analisado "in natura", pré-processado $\left(95^{\circ} \mathrm{C}\right.$ durante $5 \mathrm{~min}$ ) em salmoura $2 \%$ ( $\mathrm{NaCl}$ ) e processado a $120^{\circ} \mathrm{C} / 7 \mathrm{~min}$ (FERREIRA, 1999).

O material em conserva foi analisado no tempo zero (T0), logo após o processamento, com 30 dias de vida-de-prateleira (T1), aos 60 dias (T2) e aos 90 dias (T3) após o processamento.

Em todas as fases, o manto foi cortado com faca em pedaços de, aproximadamente, $25 \mathrm{~mm}^{2}$.

Para a análise de proteínas foram realizadas duas extrações. Na primeira foram utilizadas $5 \mathrm{~g}$ de manto e na segunda o resíduo da primeira. A primeira fração foi obtida pela homogeneização do manto de lula em liquidificador por 2 minutos, com tampão fosfato $\mathrm{pH}$ 7,5 (15,6 $\mathrm{mM} \mathrm{K}_{2} \mathrm{HPO}_{4}$; $4,3 \mathrm{mM} \mathrm{KH}_{2} \mathrm{PO}_{4}$ ), seguida de centrifugação a 5000 rpm por 20 minutos a $4^{\circ} \mathrm{C}$. Esse tampão fosfato foi codificado com a sigla TF e os dois sobrenadantes, resultantes de duas etapas de extração consecutivas, 
foram denominados fração protéica TF1 e TF2. O resíduo, resultante dessa primeira extração, foi homogeneizado em liquidificador por 2 minutos com tampão fosfato $\mathrm{KCl} \mathrm{pH} \mathrm{7,5} \mathrm{(15,6} \mathrm{mM} \mathrm{K} \mathrm{HPO}_{4} ; 4,3 \mathrm{mM}$ $\mathrm{KH}_{2} \mathrm{PO}_{4} ; 0,45 \mathrm{M} \mathrm{KCl}$ ), sendo a seguir centrifugado a 5000 rpm por 20 minutos a $4^{\circ} \mathrm{C}$. Os dois sobrenadantes (resultantes de duas extrações consecutivas) foram denominados fração protéica TFS1 e TFS2, sendo o tampão utilizado chamado de TFS. As proteínas solúveis extraídas tiveram sua concentração total mensuradas pelo método colorimétrico de BRADFORD (1976).

\subsection{ELETROFORESE}

Utilizou-se a técnica de eletroforese em gel de poliacrilamida, contendo dodecil sulfato de sódio (SDS-PAGE) (HUIDOBRO, MONTERO e BORDEIRAS, 1998). A coloração dos géis ocorreu em solução contendo ácido acético $10 \%(\mathrm{v} / \mathrm{v})$, álcool isopropílico $25 \%(\mathrm{v} / \mathrm{v})$ e Coomassie Brilliant Blue R-250 0,05\% por, aproximadamente, 40 minutos. Os géis foram descorados em solução contendo 10\% (v/v) de ácido acético e $25 \%$ (v/v) de álcool isopropílico, renovando-se a solução a cada 30 minutos até obtenção de revelação nítida (WEBER e OSBORN, 1969).

Efetuou-se o cálculo do peso molecular das frações protéicas mediante construção de curvas-padrões (PORZIO e PEARSON 1977). As corridas foram realizadas em cuba PROTEAN II xi Cell da BIO-RAD (15 mA, 16h) e as secagens no $583 \mathrm{Gel}$ Dryer da BIO-RAD $\left(80^{\circ} \mathrm{C}\right.$, 3h). No caso das proteínas com alto peso molecular foram usados os seguintes padrões da BIO-RAD (em kDa): 208 (miosina), 116 ( $\beta$-galactosidase), 84 (albumina de soro bovino) e 47 (ovoalbumina). Para as proteínas com baixo peso molecular foram utilizados os seguintes padrões da BIO-RAD (em kDa): 104 (fosforilase B), 66 (albumina de soro bovino), 47,7 (ovoalbumina), 34,6 (anidrase carbônica), 28,3 (inibidor da tripsina de soja) e 19,2 (lisozima).

Alíquotas das amostras a serem avaliadas foram recolhidas do sobrenadante e diluídas em tampão na proporção de 1:1. A solução tampão continha $3800 \mu \mathrm{L}$ de água deionizada; $1000 \mu \mathrm{L}$ de $0,5 \mathrm{M}$ Tris$\mathrm{HCl}, 800 \mu \mathrm{L}$ de glicerol, $1600 \mu \mathrm{L}$ de SDS $10 \%(\mathrm{p} / \mathrm{v}), 400 \mu \mathrm{L}$ de 2mercaptoetanol, $400 \mu \mathrm{L}$ de azul de bromofenol e pH 6,8.

Após diluição, as amostras foram submetidas à desnaturação em banhomaria a $100^{\circ} \mathrm{C}$ por 5 minutos e analisadas, imediatamente, ou estocadas a $-20^{\circ} \mathrm{C}$ para minimizar a atividade proteolítica das enzimas ainda 
presentes (PORZIO e PEARSON, 1979). As amostras submetidas ao processo de concentração foram tratadas com 10\% de ácido tricloroacético (TCA) para precipitar as proteínas (BRAAKSMA e SCHAAP, 1996) e centrifugadas a 1000 rpm por 10 minutos. Diluiu-se o precipitado em uréia 6 M (LIN e PARK, 1998).

\section{RESULTADOS E DISCUSSÃO}

\subsection{ELETROFORESE DAS PROTEÍNAS EXTRAÍDAS DO MATERIAL IN NATURA}

As frações protéicas obtidas do material "in natura", após extração (como descrito nas etapas TF1, TF2 e TFS1 da fase 1) foram analisadas por eletroforese em SDS-PAGE a 15\%. Foram utilizadas as amostras obtidas diretamente das extrações (Figura 1) e as amostras concentradas (Figura 2).

Notou-se nas extrações em que as proteínas solúveis não foram concentradas (Figura 1), que as bandas majoritárias apresentaram pesos moleculares equivalentes a 8, 29, 40, 41, 43 e 77 kDa.

Comparando-se os valores encontrados (Figura 1) com resultados da literatura (PAREDI e CRUPKIN, 1997; VERREZ-BAGNIS et al., 1999) pode-se inferir que a proteína com peso $43 \mathrm{kDa}$ refere-se à actina e a com $77 \mathrm{kDa}$ à tropomiosina, proteínas que fazem parte do complexo miofibrilar. Não foram observadas cadeias polipeptídicas com peso molecular em torno de $200 \mathrm{kDa}$, que fazem parte da composição da molécula de miosina (Figura 1). STANLEY e HULTIN (1984) evidenciaram alta atividade proteolítica do manto de lula, mesmo quando estocado sob congelamento. Tal fato geraria modificação no perfil eletroforético que seria composto por cadeia pesada de miosina (200 kDa), cadeia leve de miosina (cadeias de 20 a $30 \mathrm{kDa}$ ), paramiosina ( $110 \mathrm{kDa}$ ) e actina (40-45 kDa). Segundo os mesmos autores, a cadeia polipeptídica de actina seria resistente a essa catálise enzimática.

PAREDI e CRUPKIN (1997) observaram produtos de degradação, tanto em mantos de lula adultas quanto de jovens, mantidas sob congelamento e analisadas em gel de SDS a $10 \%$. Sugeriram que as amostras jovens apresentaram o complexo de actomiosina com baixo conteúdo da cadeia pesada de miosina e as adultas alto conteúdo de uma cadeia com $160 \mathrm{kDa}$. 
FIGURA 1 - ELETROFORESE EM GEL DE POLIACRILAMIDA COM SDS (15\%) DAS PROTEÍNAS SOLÚVEIS EM TF E TFS DO MANTO DE LULA “IN NATURA" *

TF1

TF2

TFS

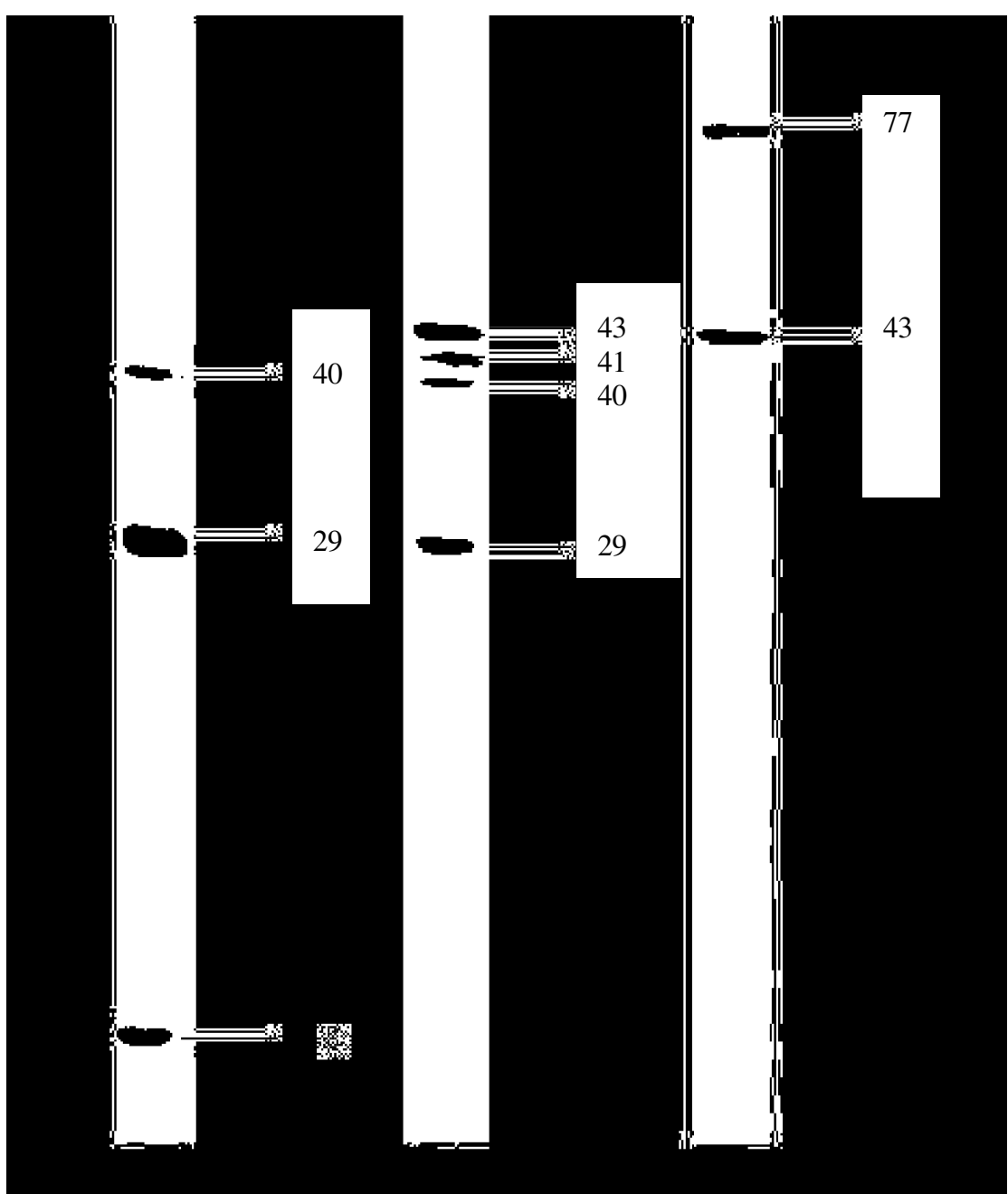

* Unidade expressa em kDa. 
RODGER et al. (1984) demonstraram que a presença de protease na musculatura do manto de lula causaria a degradação da miosina com simultâneo aparecimento de banda com 155 kDa.

A banda de actina com $43 \mathrm{kDa}$ foi observada na extração com TFS, que se destina a extrair as proteínas da fração miofibrilar (Figura 1). Porém, na segunda extração com TF, que só deveria conter proteínas da fração sarcoplasmática, essa banda ( $43 \mathrm{kDa}$ ) também foi observada (Figura 1). Sugere-se então, como padrão de proteínas sarcoplasmáticas para o manto de lula "in natura", as cadeias polipeptídicas com peso de 40, 29 e $8 \mathrm{kDa}$ (presentes apenas na primeira extração com TF).

A concentração das amostras (Figura 2), objetivando a visualização da cadeia pesada de miosina, permitiu a observação de bandas majoritárias com pesos moleculares equivalentes a 12, 82, 146, 171 e uma com peso estimado de 222 kDa (não observadas nas amostras não-concentradas). Cadeias polipeptídicas com peso molecular superior a $205 \mathrm{kDa}$ foram detectadas no axoplasma de lula. KOBAYASHI et al. (1986) observaram cadeias na faixa de $255 \mathrm{kDa}$ a $260 \mathrm{kDa}$, BEARER et al., 1996 isolaram cadeia com valor aproximado de $235 \mathrm{kDa}$ e TYTELL et al. (1990) evidenciaram proteína com $190 \mathrm{kDa}$, que seria precursora de cadeia com $220 \mathrm{kDa}$ encontrada nos neurofilamentos do axoplasma. JAFFE et al., 2001 caracterizaram essa cadeia $(220 \mathrm{kDa})$ nos neurofilamentos da lula Loligo pealei. Esse tratamento não foi efetivo para a visualização da cadeia com peso de $110 \mathrm{kDa}$, sugerida por PAREDI, DAVIDOVICH e CRUPKIN (1999) e STANLEY e HULTIN (1984) como sendo a paramiosina (cadeia presente no tecido muscular do manto de lula). Após a concentração da amostra pôde-se observar cadeia estável com peso de $82 \mathrm{kDa}$ que esteve presente nas três etapas extrativas (Figura 2).

Verificou-se que a proteína com peso 146 kDa (Figura 2) apresentou valor próximo ao da proteína C (CHEFTEL e LORIENT, 1989). As cadeias polipeptídicas com peso de 171, 41 e $12 \mathrm{kDa}$ podem ser produtos de hidrólise, causada pela alta atividade proteolítica presente na amostra (mesmo quando mantidas sob resfriamento), como sugerido por PAREDI et al. (1999) e STANLEY e HULTIN (1984). A cadeia leve de miosina não foi observada, porém a cadeia com $12 \mathrm{kDa}$ pode representar a hidrólise da mesma. Portanto, a lula "in natura" utilizada no presente trabalho apresentou padrão de identidade de proteínas sarcoplasmáticas representado por cadeias polipeptídicas com peso de 40, 29 e $8 \mathrm{kDa}$ e para as proteínas miofibrilares por cadeias com peso de 12, 43, 77, 82, 146, 171 e 222 kDa. 
FIGURA 2 - ELETROFORESE EM GEL DE POLIACRILAMIDA SDS (15\%) DAS PROTEÍNAS SOLÚVEIS EM TF E TFS DO MANTO DE LULA “IN NATURA”, APÓS CONCENTRAÇÃO*

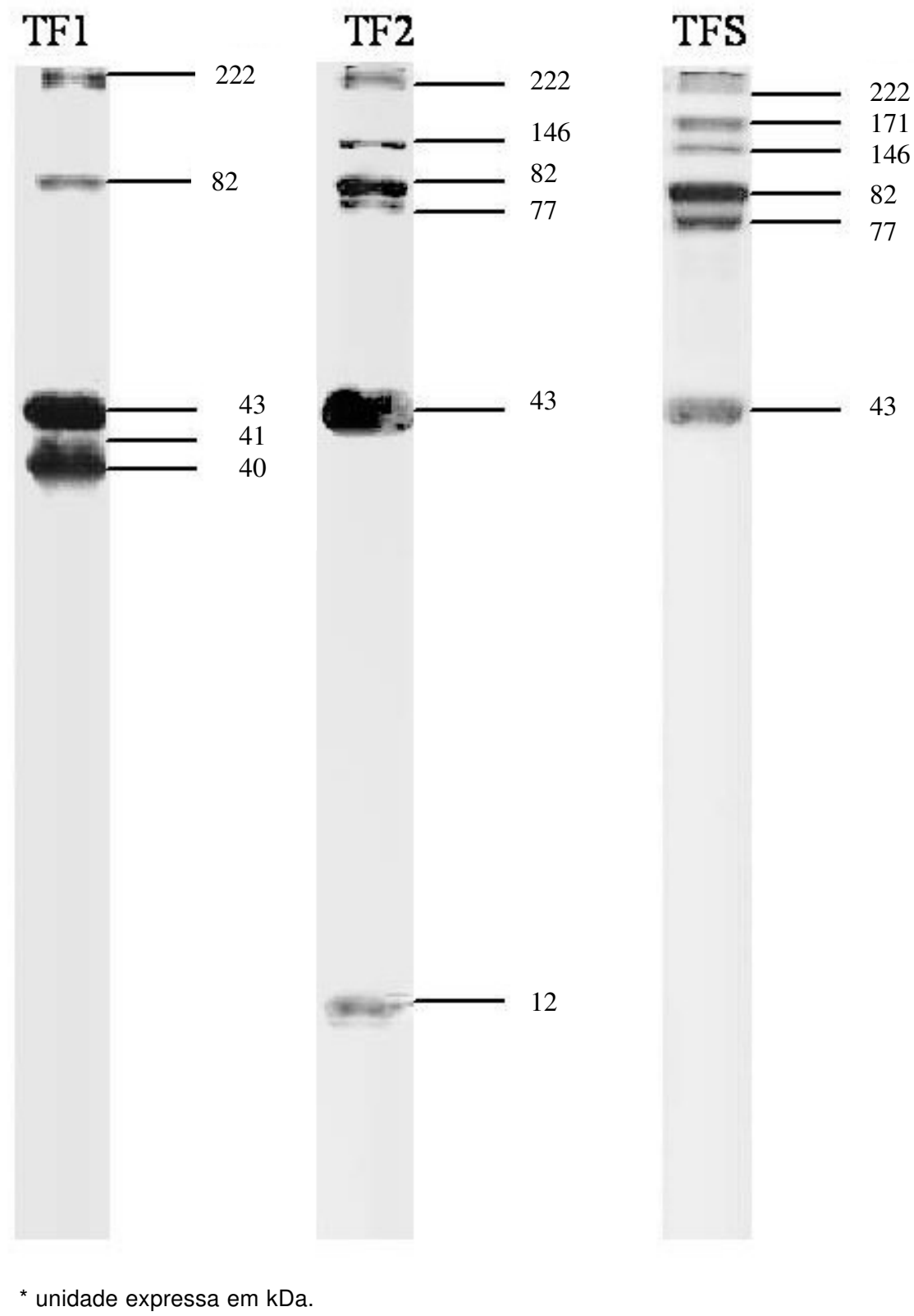




\subsection{ELETROFORESE DAS PROTEÍNAS EXTRAÍDAS E DIFUNDIDAS DO MATERIAL PRÉ- PROCESSADO E PROCESSADO}

As proteínas solubilizadas naturalmente na água de salmoura do manto pré-processado foram analisadas de acordo com o seu perfil eletroforético (SDS-PAGE) (Figura 3), tendo como parâmetro comparativo o perfil eletroforético (SDS-PAGE) da lula "in natura". A salmoura analisada apresentou 564,20 mg de proteínas (proveniente do ensaio, utilizando $70 \mathrm{~g}$ de manto de lula "in natura" e $140 \mathrm{~mL}$ de $\mathrm{NaCl} 2 \%$ ). Esse valor evidencia que para cada quilo de lula "in natura" ocorre perda de $8,06 \mathrm{~g}$ de proteína solúvel. Segundo SIKORSKI e KOLODZIEJSKA (1986), o manto de lula contém aproximadamente $18 \%$ de proteína. Assim sendo, a perda de $8,06 \mathrm{~g}$ representa decréscimo de $4,48 \%$ do total de proteínas do manto. As bandas majoritárias observadas no gel apresentaram pesos moleculares iguais a 43, 80, 83, 105 e $142 \mathrm{kDa}$.

FIGURA 3 - ELETROFORESE EM GEL DE POLIACRILAMIDA SDS (10\%) DAS PROTEÍNAS SOLUBILIZADAS NA SALMOURA USADA NO PRÉ-PROCESSAMENTO*

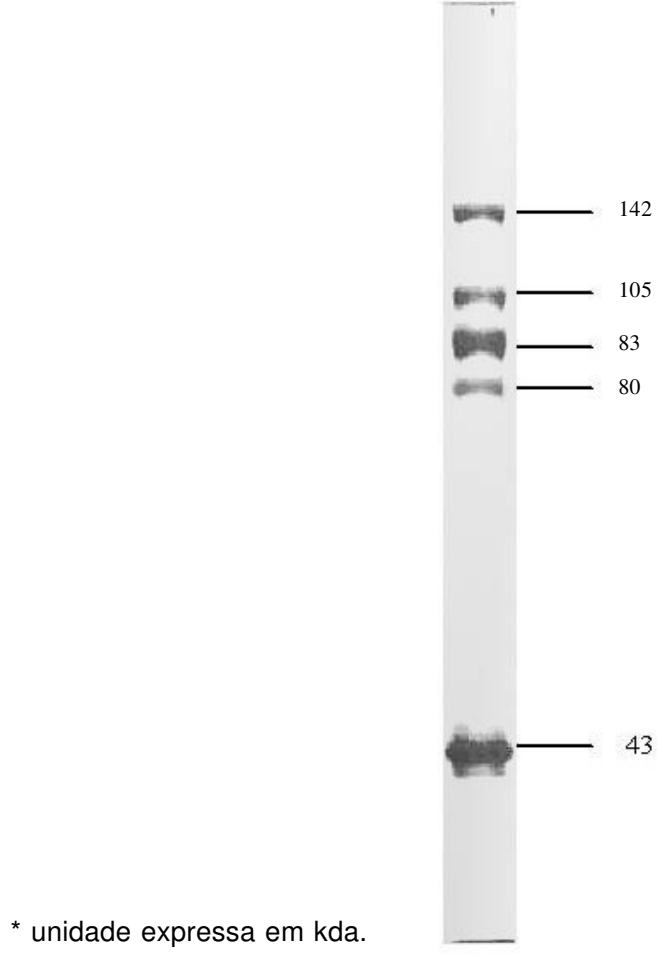


Além da presença de cadeia de actina $(43 \mathrm{kDa})$ foram também observadas as cadeias de 142, 83 e $80 \mathrm{kDa}$, que apresentam similaridade com as cadeias do material "in natura" (146, 82 e 77 kDa).

As proteínas solubilizadas naturalmente na água de salmoura do manto processado (nas etapas T0, T1, T2 e T3) foram analisadas em relação ao seu perfil eletroforético (Figura 4), tendo como parâmetro comparativo o perfil eletroforético (SDS-PAGE) da lula "in natura".

As proteínas solúveis avaliadas por eletroforese em gel de poliacrilamida SDS (Figura 4) evidenciaram bandas majoritárias com peso molecular de 43, 80 e $83 \mathrm{kDa}$. As cadeias de 43, 80 e $83 \mathrm{kDa}$ apresentaram similaridade com as cadeias de 43, 77 e $82 \mathrm{kDa}$ encontradas no material "in natura".

\section{FIGURA 4 - ELETROFORESE EM GEL DE POLIACRILAMIDA COM SDS-PAGE (10\%) DAS PROTEÍNAS SOLUBILIZADAS NA SALMOURA DA LULA PROCESSADA DAS ETAPAS TO A T3*}

T0
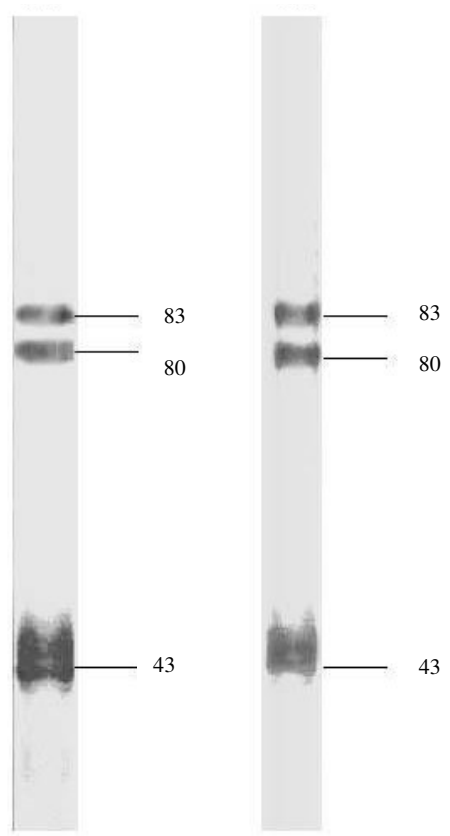

T2

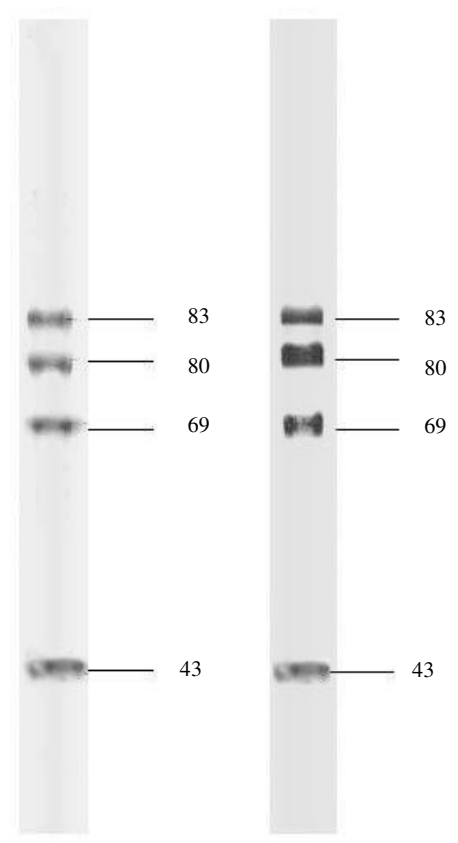

* unidade expressa em kDa. 
As proteínas do manto de lula pré-processado (solubilizadas nas quatro etapas extrativas com TF e TFS) foram analisadas em gel de poliacrilamida (SDS-PAGE) a 12\% (Figura 5). A banda majoritária obtida nas quatro etapas foi a com peso de $43 \mathrm{kDa}$. A banda com $31 \mathrm{kDa}$ só esteve presente na etapa TF1 e a com peso $41 \mathrm{kDa}$ foi observada nas etapas TF1 e TF2.

As bandas com peso de 31 e $41 \mathrm{kDa}$ revelaram similaridade com as bandas de 29 e $41 \mathrm{kDa}$ verificadas no manto do material "in natura". $\mathrm{Na}$ extração com TFS somente foi detectada a presença da banda de actina (43 kDa) não ocorrendo a presença da banda com $77 \mathrm{kDa}$ observada no material "in natura". A concentração do material gerou resposta semelhante a do material não-concentrado.

A primeira etapa de extração com TF das proteínas do manto de lula processado (T0) e das etapas do armazenamento por 90 dias (T1 a T3) foram analisadas em gel de eletroforese SDS-PAGE a 12\% (Figura 6). Não foi apresentado o gel das proteínas solubilizadas na segunda etapa de extração com TF e nas duas etapas com TFS devido à baixa concentração de proteína que as amostras revelaram.

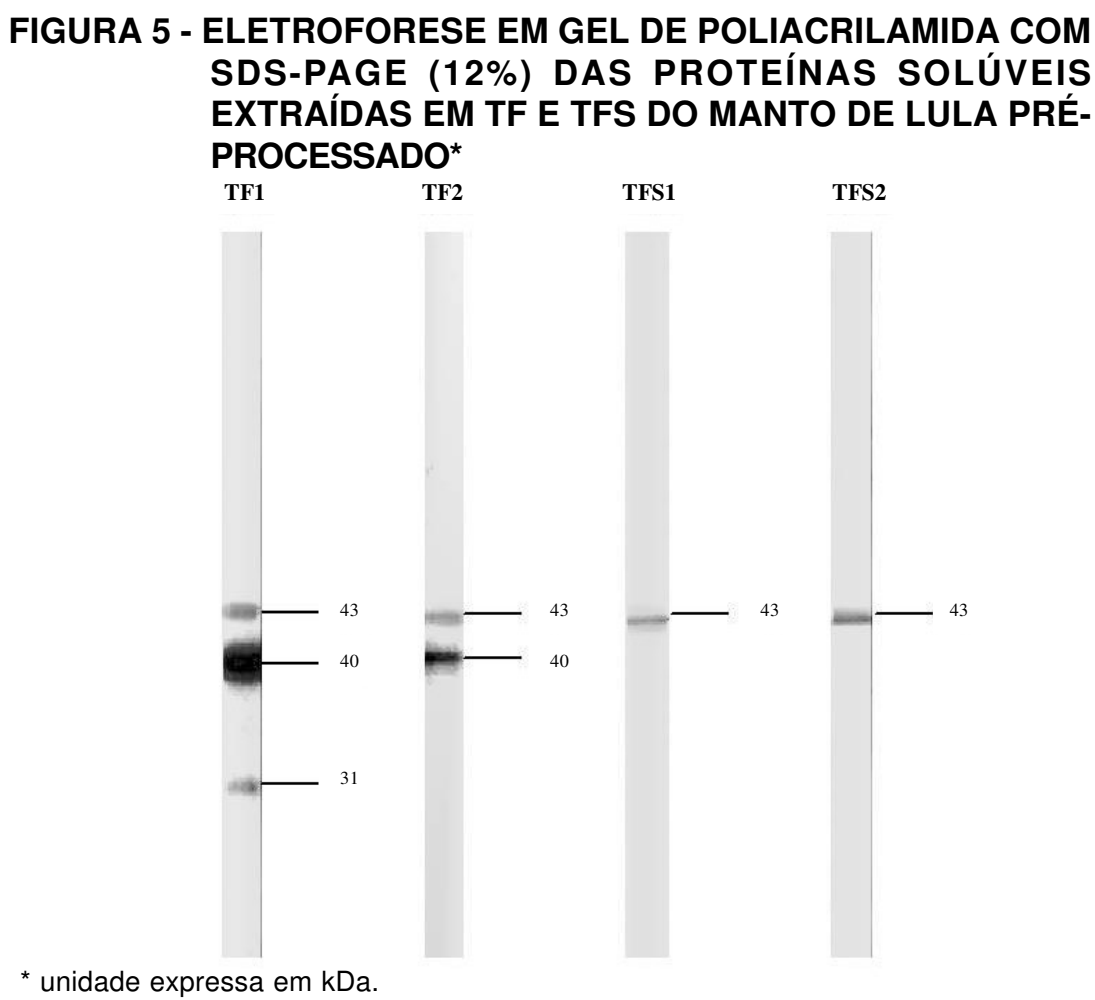


No manto processado, as bandas majoritárias encontradas apresentaram pesos moleculares equivalentes a 43, 80 e $83 \mathrm{kDa}$. A banda com $41 \mathrm{kDa}$ só foi observada na etapa T0. Cadeias com maior peso molecular, acima de $83 \mathrm{kDa}$, não foram observadas. As cadeias com 41, 43, 80, e $83 \mathrm{kDa}$ apresentaram similaridade com as cadeias de 41, 43, 77 e $82 \mathrm{kDa}$ encontradas no material "in natura". Esses resultados evidenciam que durante os três meses de armazenamento da lula em conserva, o perfil das proteínas extraídas manteve-se estável. Como não houve degradação do tecido muscular, o material encontrava-se próprio para consumo.

\section{FIGURA 6 - ELETROFORESE EM GEL DE POLIACRILAMIDA COM SDS (12\%) DAS PROTEÍNAS SOLÚVEIS EM TF DO MANTO DE LULA PROCESSADA*}

T0

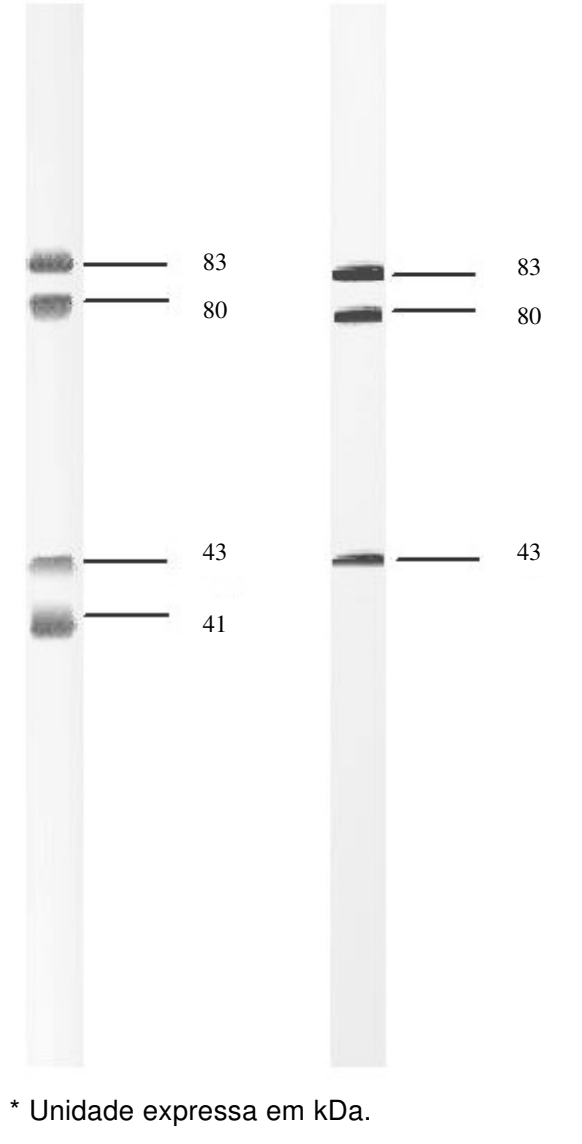

T2
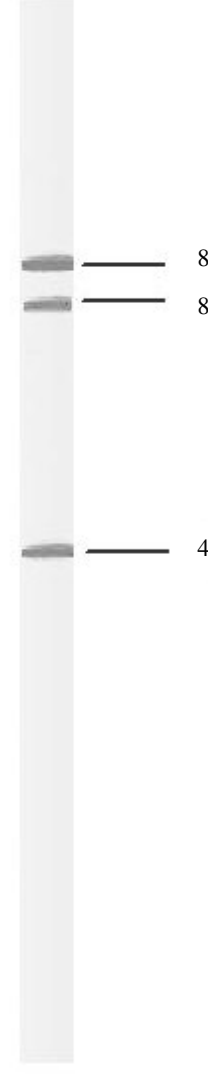

T3

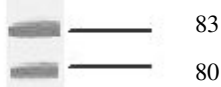


No material "in natura" observou-se (Figura 7) que o TFS foi mais eficiente na extração de proteínas com peso molecular na faixa entre $45 \mathrm{kDa}$ e $85 \mathrm{kDa}$, enquanto que as proteínas com até $25 \mathrm{kDa}$ só estiveram presentes na extração na etapa TF1. A faixa de $25 \mathrm{kDa}$ a $45 \mathrm{kDa}$ foi extraída nas três etapas, evidenciando a influência da força iônica na separação entre as proteínas sarcoplasmáticas ( $(=0,1 \mathrm{M}$, extração com tampão fosfato) e miofibrilares ( $(>0,5 \mathrm{M}$, extração com tampão fosfato salino) (ISHIOROSHI, SAMEJIMA e YASUI,1983; CÂNDIDO, NOGUEIRA e SGARBIERI, 1998; OGAWA e MAIA, 1999).

\section{FIGURA 7 - ANÁLISE DE DISTRIBUIÇÃO DO BANDEAMENTO PROTÉICO AO LONGO DAS ETAPAS EXTRATIVAS NO MATERIAL "IN NATURA"}

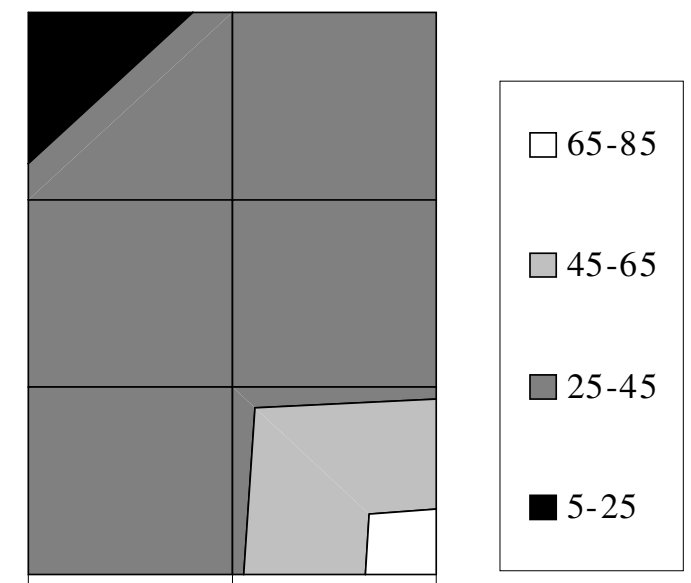

TF 1

TF2

TFS

Etapas extrativas

A ação do calor causa modificações nas proteínas constituintes do tecido muscular (CHAN, GIL e PAULSON, 1993; PAREDI, DAVIDOVICH e CRUPKIN, 1999). CHENG e PARRISH (1979) propuseram o uso da eletroforese em gel de poliacrilamida (SDS-PAGE) para a detecção das mudanças que ocorrem nas proteínas miofibrilares durante o aquecimento. Pelo comportamento das distribuições dos pesos moleculares e as cadeias polipeptídicas extraídas com TF1 pode-se observar que depois que o manto passa pela fase transitória de preparação (préprocessamento) e pelo processo de apertização (T0), o bandeamento 
sofre estabilização (Figura 8). Na Figura 8 pode-se notar que de T0 a T3 as faixas de pesos moleculares com $25 \mathrm{kDa}$ a $85 \mathrm{kDa}$ tornam-se estáveis ao longo do período de armazenamento estudado, evidenciando integridade do manto de lula durante esse período.

\section{FIGURA 8 - ANÁLISE DE DISTRIBUIÇÃO DO BANDEAMENTO PROTÉICO AO LONGO DAS ETAPAS EXTRATIVAS COM TF1 DE TODAS AS FASES*}
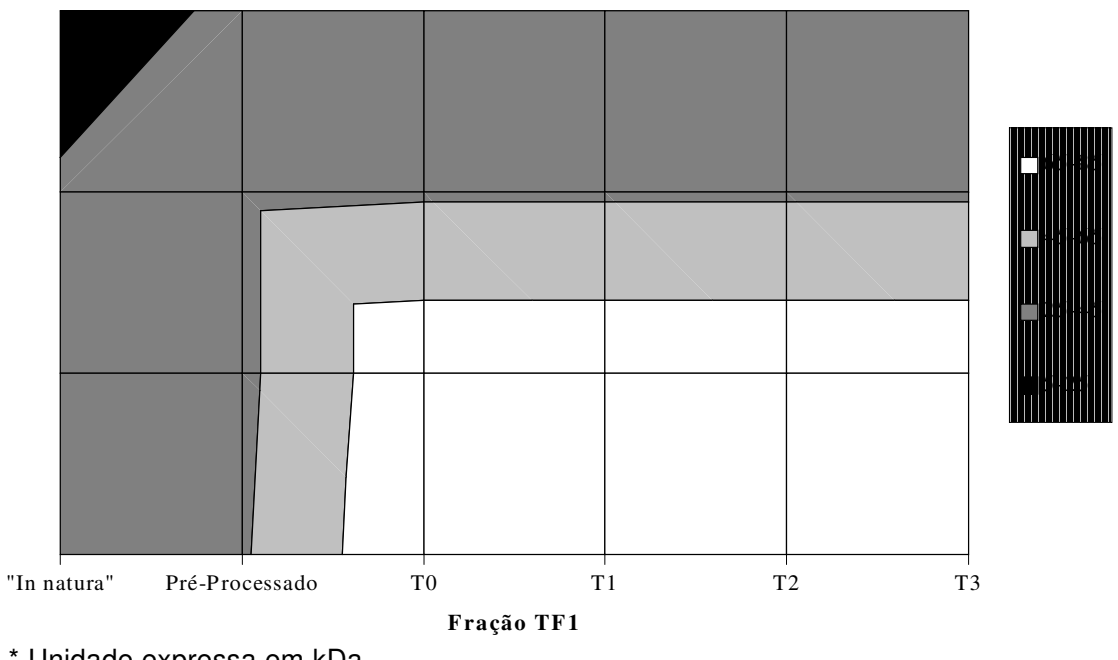

Verificou-se que as bandas na faixa abaixo de $25 \mathrm{kDa}$ só são encontradas no material "in natura". A faixa de $25 \mathrm{kDa}$ a $45 \mathrm{kDa}$ foi a única que esteve presente desde o material "in natura" até o tempo 3 (T3) (Figura 8).

A banda com $43 \mathrm{kDa}$ (actina) demanda atenção, pois esteve presente em todas as etapas extrativas. A banda com $83 \mathrm{kDa}$ revelou característica diferencial por não apresentar similaridade com nenhuma das proteínas encontradas em músculo estriado de seres vivos do reino Animaliae. Sugere-se que essa banda seja utilizada como marcador do tecido muscular do manto da lula Doryteuthis plei.

\section{CONCLUSÃO}

A lula "in natura" utilizada no presente trabalho apresentou padrão de identidade de proteínas sarcoplasmáticas representado por cadeias 
polipeptídicas com peso de 40, 29 e 8 kDa e para as proteínas miofibrilares por cadeias com peso de 12, 43, 77, 82, 146, 171 e $222 \mathrm{kDa}$. Na etapa de pré-processamento de manto de lula ocorre perda de proteínas para água de salmoura com valores equivalentes a $8,06 \mathrm{~g}$ de proteínas para cada quilograma de lula "in natura". Assim, as cadeias polipeptídicas liberadas para a salmoura são as com peso molecular de 146, 82, 77 e $43 \mathrm{kDa}$ oriundas do manto de lula "in natura".

Obteve-se padrão de identidade do manto de lula processada, com cadeias polipeptídicas com pesos de $43 \mathrm{kDa}, 80 \mathrm{kDa}$ e $83 \mathrm{kDa}$, que se manteve estável durante os 90 dias de armazenamento. Tal fato evidencia que durante esse período de estocagem, o manto de lula manteve-se próprio para consumo.

\begin{abstract}
USE OF ELECTROPHORESIS (SDS-PAGE) FOR THE STUDY OF PROTEINS FROM “IN NATURA" AND PROCESSED SQUID MANTLE MUSCULAR TISSUE

In the present work the modifications of the proteins in the of squid mantle muscular tissue (Doryteuthis plei BLAINVILLE, 1823) were studied, "in natura", pre-processed $\left(95^{\circ} \mathrm{C} / 5 \mathrm{~min}, \mathrm{NaCl} 2 \%\right)$ and processed $\left(120^{\circ} \mathrm{C} / 7 \mathrm{~min}, \mathrm{NaCl} 2 \%\right)$. The proteins naturally solubilized in brine resulting from the pre-processing and processing were also analyzed. The processed samples were evaluated during a period of storage of 90 days. The mantle proteins were extracted in phosphate buffer $\left(15.6 \mathrm{mM} \mathrm{K}_{2} \mathrm{HPO}_{4}\right.$; $4.3 \mathrm{~mm} \mathrm{KH} \mathrm{PO}_{4} ; \mathrm{pH} 7.5$ ) and saline phosphate buffer(15.6mM K $\mathrm{HPO}_{4} ; 4.3 \mathrm{mM} \mathrm{KH}_{2} \mathrm{PO}_{4}$; $0.45 \mathrm{M} \mathrm{KCL} ; \mathrm{pH} 7.5)$. The soluble proteins obtained were quantified by a colorimetric method. The analysis using the poliacrylamide gel containing sodium dodecil sulphate (SDS -PAGE) was used to characterize the polypeptide chains of the soluble proteins studied. An identity pattern of the "in natura" squid was obtained with a profile in SDSPAGE showing a series of polypeptide chains varying from $8 \mathrm{kDa}$ to $222 \mathrm{kDa}$. The identity pattern obtained for the processed squid mantle presented polypeptide chains with a profile of 43,80 and $83 \mathrm{kDa}$. The polypeptide profile was stable during the 90 days of storage, indicating good preservation of this seafood when stored after processing in brine form.
\end{abstract}

KEY-WORDS: THERMAL TREATMENT; Doryteuthis plei; PROTEINS.

\title{
REFERÊNCIAS
}

1 ANDO, M.; ANDO, M.; TSUKAMASA, Y.; MAKINODAN, Y.; MIYOSHI, M. Muscle firmness and structure of raw and cooked arrow squid mantle as affected by freshness. Journal of Food Science, v.64, n.4, p. 659-662, 1999.

2 AKTERIAN, S. Studying and controlling thermal sterilisation of Convection-heated canned foods using functions of sensitivity. Journal of Food Engineering, v.29, p.329-338, 1996. 
3 AOYAMA, S.; HINOUE, Y.; TAKAHASHI, H.; YOSHIMITSU, Y.; KUSAJIMA, Y.; HIRONO, T.; TAKAYANAGI, N.; AKAO, N.; KONDOU, K. Clinical study of ten cases with acute abdomen after eating raw firefly squid (Watasenia scintillans, HOTARUIKA), which are probably due to type $X$ larvae of the suborder spirurina. Nippon Shokakibyo Gakkai Zasshi., v.93, n.5, p.312-321, 1996.

4 BEARER, E.L.; DEGIORGIS, J.A.; JAFFE, H.; MEDEIROS, N.A.; REESE, T.S. An axoplasmic myosin with a calmodulin-like light chain. Proc. Natl. Acad. Sci., USA., v.93, n.12, p.6064-6068, 1996.

5 BRAAKSMA, A.; SCHAAP, D.J. Protein analysis of the common mushroom Agaricus bisporus. Postharvest Biology Technology, v.7, p.119-127, 1996.

6 BRADFORD, M.M. A rapid and sensitive method for the quantification of microgram quantities of protein utilizing the principle of protein-dye binding. Analytical Biochemistry, v.72, p.248-254, 1976.

7 CÂNDIDO, L.M.B.; NOGUEIRA, A.K.; SGARBIEIRI, V.C. Propriedades funcionais de concentrados protéicos de pescado preparados por vários médodos. Brazilian Journal of Food Technology, v.1, n.1,2, p. 77-89, 1998.

8 CHAN, J.K.; GILL, T.A.; PAULSON, A.T. Thermal aggregation of myosin subfragments from cod and hering. Journal of Food Science, v. 58, n. 5, p. 1057-1061, 1993.

9 CHEFTEL, J.; CUQ, J.; LORIENT, D. Proteínas alimentarias: bioquímica propiedades funcionales - valor nutricional modificaciones químicas. Zaragora: Acribia, 1989. p. 144.

10 CHENG, C.S.; PARRISH JR, F.C. Heat-induced changes in myofibrillar proteins of bovine longissimus muscle. Journal of Food Science, v.44, n.1, p.22-24, 1979.

11 FERREIRA, L.F.D. Degradação térmica da textura e cor no processamento de lula (Dorytheutis brasiliensis). Seropédica, 1999. 76 p. Dissertação (Mestrado em Ciência e Tecnologia de Alimentos), Universidade Federal Rural do Rio de Janeiro.

12 HSU, C.K.; KOLBE, E.; MORRISSEY, M.T.; CHUNG, Y.C. Protein denaturation of frozen Pacific Whiting (Merluccius productus) fillets. Journal of Food Science, v.58, n.5, p.1055, 1993.

13 HUIDOBRO, A.; MONTERO, P.; BORDERIAS, A.J. Emulsifing properties of an ultrafiltered protein from minced fish wash water Food Chemistry, v.61, n. 3, p.339-343, 1998.

14 ISHIOROSHI, M.; SAMEJIMA, K.; YASUI, T. Heat-induced gelation of myosin filaments at a low salt concentration. Agric. Biol. Chem., 
v.47, n.12, p.2809-2816, 1983.

15 JAFFE, H.; SHARMA, P.; GRANT, P.; PANT, H. Characterization of the phosphorylation sites of the squid (Loligo pealei) high molecular-weight neurofilament protein from giant axon axoplasm. J. Neurochem., v.76, n.4, p. 1022-1031, 2001.

16 KOBAYASHI, T.; TSUKITA, S.; TSUKITA, S.; YAMAMOTO, Y.; MATSUMOTO, G. Subaxolemmal cytoskeleton in squid giant axon. I. Biochemical analysis of microtubules, microfilaments, and their associated high-molecular-weight proteins. J. Cell. Biol., v.102, n.5, p. 1699-1709, 1986.

17 KONNO, K.; ARAI, K.; WATANABE, S. Myosin-linked calcium regulation in squid mantle muscle. Light-chain components of squid myosin. $\mathbf{J}$. Biochem., v.86, n.6, p.1639-1650, 1979.

18 KUGINO, M.; KUGINO, K. Changes in the microestructure and rheological properties of squid mantle due to cooking in a $\mathrm{NaCl}$ solution and soy sauce. J. Home Econ. Jap., v.46, p.751-757, 1995.

19 LIN, T.M.; PARK, J.W. Solubility of salmon myosin as affected by conformational changes at various ionic strengths and $\mathrm{pH}$. Journal of Food Science, v.63, n.2, p.215-218, 1998.

20 NAITO, F.; TAKAHASHI, S.; SATO, Y.; NOGUCHI, S.; NAITO, H.; TAKANA, T. Changes on the physical properties and sensory evaluation of squid muscle by vacuum cooking. J. Home Econ. Jap., v. 47, p.153-159, 1996.

21 NAKASHIMA, H.; AKAGI, M.; MIYABE, S.; IWASAWA, H. Two unusual cases of a foreign body in the oral cavity caused by eating raw squid. Acta. Otolaryngol. Suppl., v.522, p.104-107, 1996.

22 NAVANKASATTUSAS, S.; LUND, D.B. Monitoring and controlling thermal processes by on-line measurement of accomplished lethality. Food Technology, v.43, n3, p.79-93, 1978.

23 OGAWA, M.; MAIA, E.L. Manual de pesca: ciência e tecnologia do pescado. São Paulo: Livraria Varela, 1999. p. 30. v. 1.

24 PAREDI, M.E.; CRUPKIN, M. Biochemical properties of actomyosin from frozen stored mantles of squid (Illex argentinus) at different sexual maturation stages. J. Agric. Food Chem., v.45, p.1629-1632, 1997.

25 PAREDI, M.E.; DAVIDOVICH, L.A.; CRUPKIN, M. Thermally induced gelation of squid (IIlex argentinus) actomyosin. Influence of sexual maturation stage. J. Agric. Food Chem., v.47, p.35923595, 1999.

26 PORZIO, M.A.; PEARSON, A.M. Improved resolution of myofibrillar 
proteins with sodium dodecyl sulfate-polyacrylamide gel eletrophoresis. Biochimica et Biophysica Acta, v.490, p. 27-34, 1977.

27 PORZIO, M.A.; PEARSON, A.M. Instability of SDS denatured protein prepared from muscle myofibrils. Meat Science, v.3, p. 225-260, 1979.

28 RODGER, G.; WEDDLE, R.B., CRAIG, P.; HASTINGS, R. Effects of alkaline protease activity on some properties of comminute squid. Journal of Food Science, v.49, p.117-123, 1984.

29 ROPER, C.F.E.; SWEENEY, M.J.; NAUEN, C.E. Cephalopods of the world. An annotated and illustrated catalogue of species of interest to fisheries. Rome: FAO, 1984. v.3, 277 p. (FAO Fisheries Synopsis, 125)

30 SIKORSKI, Z.E.; KOLODZIEJSKA, I. The composition and properties of squid meat. Food Chemistry, v.20, p.213-224, 1986.

31 STANLEY, D.W.; HULTIN, H.O. Quality factors in cooked North Atlantic squid. Canadian Institute of Food Sci. and Technol. J., v.15, n.4, p.277-282, 1982

32 STANLEY, D.W.; HULTIN, H.O. Protoelytic activity in North American squid and its relation to quality. Canadian Institute of Food Sci. and Technol. J., v.17, n.3, p.163-167, 1984.

33 STANLEY, D.W.; SMITH, A.K. Microstructure of squid muscle and its influence on texture. Canadian Institute of Food Sci. and Technol. J., v.17, n.4, p.209-213, 1984.

34 TYTELL, M.; PANT, H.C.; GAINER, H.; HILL, W.D. Characterization of the distinctive neurofilament subunits of the soma and axon initial segments in the squid stellate ganglion. J. Neurosci. Res., v. 25, n.2, p.153-161, 1990

35 UENG, Y.E.; CHOW, C.J. Textural and histological changes of different squid mantle muscle during frozen storage. Journal of Agricultural and Food Chemistry, v.46, n.11, p.4728-4733, 1998.

36 VERREZ-BAGNIS, V.; NOEL, J.; SAUTEREAU, C.; FLEURENCE, J. Desmin Degradation in Postmortem Fish Muscle. Journal of Food Science, v.64, n.2, p.239-242, 1999.

37 WEBER, K.; OSBORN, M. The reliability of molecular weight determinations by dodecyl sulfate-polyacrylamide gel electrophoresis. J. Biol. Chem., v.244, n.16, p.4406-4412, 1969. 